\title{
O surfe brasileiro e as mídias sonora e audiovisual nos anos $1980^{1}$ Brazilian surf and the sound and audio-visual
media in 1980 years
}

Rafael Fortes I raffortes@hotmail.com Professor da Universidade Federal do Estado do Rio de Janeiro (UNIRIO). Doutor em Comunicação, historiador e jornalista. Editor de Recorde: Revista de História do Esporte e pesquisador do Sport: Laboratório de História do Esporte e do Lazer (PPGHC/UFRJ).

\section{Resumo}

Esporte midiático por excelência, o surfe estabeleceu uma série de relaçôes com a cultura (música, televisão, cinema), incluindo imbricaçôes com a cultura pop. Estas manifestaçôes foram fundamentais para a divulgação da modalidade e a construção de uma imagem em torno da mesma para o público externo, assim como a discussão e a configuração de valores para os membros de sua subcultura. No Brasil, este processo teve notável força durante a década de 1980. O artigo mapeia as imbricaçôes entre surfe e mídias sonoras e audiovisuais no período, tendo como fonte principal a revista Fluir.

Palavras-chave: Surfe; Revista Fluir; Rádio; Cinema; Armação Ilimitada.

\section{Abstract}

A media sport per excellence, surfing established many links with culture (music, television, film), including imbrications with pop culture. These trends were important for the process of making it known and for the building of an image for the external public, as well as the configuration of values for the members of the subculture. In Brazil, this process had a notable strength during the 1980's. The article summarizes the imbrications between surfing and sound and audiovisual media in that period, with Fluir magazine as its main source.

Keywords: Surfing; Fluir Magazine; Radio; Cinema; Armação Ilimitada. 


\section{Introdução}

Diversos autores têm chamado a atenção para as ligaçóes entre esporte, mídia e indústria do entretenimento (Beattie, 2003; Booth, 2001; Borges, 2003; Castro, 2003; Fisher, 2005; Fortes e Melo, 2009; Melo, 2003; Scott, 2005; Stedman, 1997; Wheaton e Beal, 2003). Como define um deles, observa-se a construção "[d]esse cenário multimídia, no qual o esporte moderno foi transformado" (PILATTI, 2006). Nenhum dos estudos mencionados diz respeito à década de 1980, quando a imbricação entre os três setores não chamava tanto a atenção dos pesquisadores. Este artigo, que se insere na pesquisa de doutorado que investigou as relaçóes entre surfe e mídia no período mencionado, parte da análise da revista Fluir para mapear manifestaçóes ligadas à modalidade e divulgadas nas mídias sonoras e audiovisuais no Brasil. Mais especificamente, se debruça sobre as mídias sonora (rádio e música) e audiovisual (cinema, televisão e vídeo).

Discutir a relação entre surfe e cultura pop significa articular o objeto de estudo com aspectos da vida social e da comunicação social. Este foi um dos caminhos apontados por Pierre Bourdieu para o estudo do esporte pelas ciências humanas:

[...] esse espaço dos esportes não é um universo fechado sobre si mesmo. Ele está inserido num universo de práticas e consumos, eles próprios estruturados e constituidos como sistema. Há boas razóes para se tratar as práticas esportivas como um espaço relativamente autônomo, mas não se deve esquecer que esse espaço é o lugar de forças que não se aplicam só a ele. Quero simplesmente dizer que não se pode estudar o consumo esportivo, se quisermos chamá-lo assim, independentemente do consumo alimentar ou do consumo de lazer em geral (1990, 210).

Embora jamais tenha se dedicado sistematicamente ao assunto, o sociólogo aponta a necessidade de contemplar, nos estudos sobre esporte, a inserção do mesmo no contexto social. No que diz respeito à publicação em questão, seu sucesso está relacionado à emergência do jovem como sujeito e como consumidor, processo do qual o esporte é apenas uma parte. No contexto dos anos 1980, pode-se mencionar o notável crescimento do surfe e de sua indústria, ao menos no plano da divulgação midiática, ocupando espaços em muitos outros produtos, veículos e mídias. Portanto, mapear a presença do surfe em outras mídias, mesmo de forma breve, significa matizar o papel desempenhado por Fluir. Esta não foi criada no vácuo ou deteve o monopólio das representaçóes sobre o esporte. Todos esses fenômenos fazem parte do contexto em que Fluir e os temas que cobre são recebidos pelo público.

Esse efeito de apropriação social faz com que, a todo momento, cada uma das 'realidades' oferecidas sob o nome de esporte seja marcada, na objetividade, por um conjunto de propriedades que não estão inscritas na definição puramente técnica, que podem até ser oficialmente excluidas dela, e que orientam as práticas e as escolhas (entre outras coisas, dando um fundamento objetivo aos juizos do tipo 'isso é coisa de pequeno burguês' ou 'coisa de intelectual', etc.) (BOURDIEU, 1990, 213-4).

A citação levanta um ponto importante a se considerar nos estudos 
de esporte: uma prática pode ter diferentes significados ao longo do tempo, relacionados a fatores como quem a realiza e que valores lhe são atribuídos socialmente (intelectualidade, riqueza material, brutalidade, estilo etc.). A articulação com diferentes manifestaçóes da cultura pop é importante para o desenvolvimento da subcultura do surfe, na medida em que estas são decisivas para a representação do mesmo na sociedade e para atrair para a indústria do surfe um grande número de consumidores, muitos dos quais não farão parte da subcultura. ${ }^{2}$ As subseçôes a seguir desmembram o tema, tratando de mídia sonora e audiovisual.

\section{Surfe e mídia sonora}

Desde o início, Fluir reservou espaço para a música. A edição inaugural trouxe um artigo atacando os preconceitos que cercam o rock no Brasil. ${ }^{3} \mathrm{~A}$ intervenção agradou em cheio uma leitora, para quem o ritmo tem muitas afinidades com "quem curte surf, vôo livre, enfim liberdade". ${ }^{4} \mathrm{O}$ número três levou a música para a capa, com a chamada "Som: Stones Devo". O artigo sobre a banda Devo fazia menção a skate ${ }^{5}$, enquanto o dedicado aos Rolling Stones não aludia a qualquer esporte (havia sido publicado na Folha de S. Paulo e "reproduzido sob permissão do autor"). ${ }^{6}$ A seção de música completava-se com a lista intitulada "OS 10 DO MÊS". Dividida em "nacionais" e "importados", compunha-se, em sua maioria, por bandas de pop e rock. Chegara-se a ela, segundo informava o texto,

através de pesquisas realizadas nas principais casas noturnas; lojas de discos e da opinião da moçada que curte esportes radicais (surf, skate, bicicross, vôo, etc.). Agora é a sua vez, mande suas opinióes para a FLUIR, e vejamos se seu grupo será o melhor do mês. (Som, Fluir n. 3, mar 1984)

Na edição seguinte, novo chamado à participação: "o objetivo desta seção é cada vez mais basear-se apenas em cartas enviadas por vocês, portanto, mexam-se".

A lista tinha a finalidade de servir como termômetro das preferências dos jovens aficionados por esportes radicais. Contudo, esse tipo de iniciativa acaba funcionando também de forma inversa, ou seja, como fonte de informação para os próprios adeptos da subcultura a respeito de que bandas e músicas devem ouvir. Publicaçôes nacionais e importadas participaram ativamente da formação do gosto musical dos entusiastas de esportes radicais. ${ }^{8}$ Títulos estrangeiros circulavam bastante entre os membros da subcultura do surfe. Incrementavam o interesse pelo esporte, traziam novidades, disseminavam gostos e - o que é fundamental - serviram como modelos inspiradores para quem se dispôs a criar similares por aqui. ${ }^{9}$ Segundo Gutenberg (1989, 113-4), "depois de ler muita revista americana, Pecegueiro resolveu fazer a sua própria revista", referindo-se à pioneira Brasil Surf, de 1975. Sociedade entre Alberto Pecegueiro e Flavio Dias, saiu de circulação em 1979, acompanhando a decadência do esporte (GUTENBERG, 1989, 114).

A publicação de imagens feitas pelo fotógrafo internacional Craig Peterson propiciou que se revelasse a importância do contato com publicaçôes do exterior: 
Eu, o Carlos e o Bruno somos da geração que viveu a adolescência na época do 'milagre brasileiro' [...] o dólar era barato e os produtos importados, como as revistas de surf, eram acessiveis a muita gente. A revista americana SURFER, por exemplo, chegou a vender mais de 10 mil exemplares por edição num país em que pouquíssimas pessoas falavam inglês. Nós crescemos com ela [...]

Aquele tipo de trabalho nos influenciou demais.

Os três citados trabalhavam em Fluir - dois deles, sócio-fundadores. A facilidade de acesso a Surfer se insere no boom de consumo da classe média brasileira durante os anos 1970. Revistas como ela contribuíram, no passado, para os então adolescentes se apaixonarem pelo surfe e, mais à frente, para a idéia de trabalharem com o esporte: fotografando (Carlos Lorch e Bruno C. Alves) e criando sua própria publicação (Alexandre Andreatta e Bruno C. Alves). ${ }^{10}$

Castro (2003, 93) e Goldenstein (1991) assinalam a freqüência do hábito de ouvir música e sua importância entre jovens e adolescentes. Um dos fatores que marcam a passagem de simples praticante ou admirador de esportes radicais à condição de membro da subcultura é o compartilhamento de preferências musicais com os demais integrantes, os quais em geral são ouvintes assíduos de um (ou mais) estilo musical específico.

A música foi particularmente importante como elemento agregador no skate, cujos adeptos, durante os anos 1980, ouviam, sobretudo, new wave, punk, rock e hardcore. Perguntado sobre semelhanças entre skate e bicicross, um piloto e skatista responde que várias manobras são parecidas, mas que " $a$ moçada de skate tem mais o pique de horrorizar, ouvindo som punk, new wave". ${ }^{11}$ $\mathrm{O}$ gosto musical é trazido à baila para evidenciar as diferenças entre os grupos, não apenas no tipo de música ouvido, mas nos sentidos atribuídos ao gosto, como o de "horrorizar" as pessoas. Uma legenda de foto vinculava a radicalidade de um skatista à participação no movimento punk: "Tatu (coquetel molotov) carrega todas suas influências punks numa das manobras que ainda hoje é de destaque". 12 Reforçando as fronteiras entre as modalidades, as dicas do quadro "som para skate" configuravam um espaço à parte, separado da cobertura de música da revista.

O gênero musical mais destacado foi o rock, que se caracteriza pela reivindicação de valores como rebeldia e contestação e, ao mesmo tempo, uma inserção comercial profunda (VILLAÇA, 2002). Exemplo foi o interesse despertado pelo festival Rock in Rio. Em setembro de 1984, um artigo sem assinatura e semelhante a um release chamava a atenção para o festival Rock in Rio e dizia que "em janeiro o Brasil vai parar. [...] Resumindo: VAI SER DEMAIS! A FLUIR estará lá, e vocêe?"13 Meses depois, a revista trouxe uma matéria com a cobertura do evento.

A explosão do rock nacional - e, particularmente, de certas bandas - nos anos 1980 se apoiou na existência de emissoras de rádio que tocavam fitas demo de artistas então desconhecidos e sem contrato com gravadora (SILVA, 2008). A principal delas foi a Fluminense FM, de Niterói (RJ), cujo papel no crescimento do rock nacional é constantemente ressaltado pelos próprios artistas. ${ }^{14} \mathrm{~A}$ 
emissora levou ao ar músicas e notícias relacionadas ao surfe; divulgou, cobriu e até organizou e patrocinou competiçóes como a Copa Rádio Fluminense $83^{15}$ e a Copa Fluminense FM de Surf (1984) ${ }^{16}$, ambas realizadas na praia de Itacoatiara (Niterói). Apelidada a "Maldita", chegou a apoiar campeonatos fora do estado do Rio de Janeiro, entre eles a etapa de Ubatuba (SP) do primeiro Circuito Brasileiro de Surf Profissional, em 1987. ${ }^{17}$ Estabeleceu parceria para divulgaçáo mútua com o Realce (programa televisivo sobre esportes radicais do Rio de Janeiro). Artistas cujas músicas tocavam na rádio eram entrevistados ou tinham seus videoclipes exibidos no programa, ao passo que a emissora veiculava canções que integravam o gosto musical dos surfistas (SILVA, 2008).

Diversas estaçôes de rádio lançaram mão da forma mais comum de divulgação - propaganda paga - e publicaram anúncios de página inteira em Fluir: Fluminense, ${ }^{18}$ Transamérica FM, ${ }^{19} 89$ FM (Sáo Paulo/SP), 95 FM (Santos/SP) ${ }^{20}$ e Bandeirantes FM (São Paulo, Porto Alegre e Salvador). ${ }^{21}$

Voltando ao rock brasileiro, as seçôes de música e de notas noticiavam lançamento de discos e as gravadoras veiculavam propagandas dos mesmos. O registro do lançamento de "dois discos do melhor rock nacional"22, de Lobão e Plebe Rude, apareceu na edição posterior àquela que estampou anúncios de página inteira de ambos. Boa parte dos artistas de maior sucesso nos anos 1980 foi entrevistada por Fluir no período: Camisa de Vênus, Os Paralamas do Sucesso, Ultraje a Rigor, Rita Lee, Evandro Mesquita, Léo Jaime. O conteúdo das conversas versava sobre o trivial (carreira, novidades, influências, estilo) e a relação com os esportes radicais.

Integrantes do Ultraje a Rigor, cujo disco Nós vamos invadir sua praia, lançado em 1985, fez enorme sucesso, elogiaram o gosto musical dos surfistas e destacaram a afinidade entre estes e sua música. Quando os entrevistadores lembraram que "surfista e roqueiro sempre foram considerados marginais", um dos membros respondeu: "quem é que manda nesta merda aqui? São os jovens, então o negócio agora é rock e surf." $23 \mathrm{Da}$ mesma forma, membros da banda Replicantes chamaram a atenção para a articulação entre música e surfe e explicaram que não surfavam, mas admiravam o esporte. A revista mencionou que a canção "'Surfista Calhorda' teve uma grande aceitação entre a galera do surf exatamente porque retrata uma realidade surfética." O baterista Carlos Gerbase, compositor da música, respondeu que buscou "pegar a coisa comercial porque surgiram centenas de surf shops. Acho que lá em Porto Alegre tem mais surf shop do que aqui em São Paulo." $24 \mathrm{O}$ "surfista calhorda" criticado na letra usa roupas de surfe e é proprietário de duas lojas, mas "quando entra n’água [...] ele não surfa nada".

Um dos pontos destacados era a presença dos esportistas em shows, como nos da banda Camisa de Vênus realizados em São Paulo, em que "skatistas [... dominavam completamente a área em frente ao palco, com suas danças 'pogo' $e$ 'power diving' (se jogando de cima do palco de todas as formas) [...]”. ${ }^{25}$

O fato de um ou mais integrantes de uma banda ser adepto ou admirador do surfe sempre recebia destaque, como no caso da californiana Oingo Boingo. ${ }^{26}$ Músicos como Léo Jaime e Herbert Vianna surfavam no Rio de 
Janeiro. Um artigo narrando a história do surfe no lendário município de Saquarema (RJ) destacou a ligação entre a modalidade e a música, especialmente o pop/rock nacional que surgia naquele momento. O surfista Zeca Mendigo, "autor da música que lançou a Blitz com o hit 'Você náo soube me amar', a teria composto no quintal de uma casa em Saquarema, onde também morara o cantor Evandro Mesquita ${ }^{27}$ - vocalista da Blitz e ator, Mesquita interpretou um surfista em Menino do Rio.

Por último, vale destacar a presença da música nos campeonatos. Durante o dia, no sistema de som; à noite, nas festas e shows. A inclusão de shows na programação dos campeonatos datava da década anterior, quando foram realizados eventos como Festival Rock, Surf e Brotos, na praia da Joaquina (Florianópolis, SC) e Som, Sol e Surf (Saquarema, RJ) (GUTENBERG, 1989, 146; BUENO, 2005, 167).

Em Itacoatiara (Niterói, RJ), a Fluminense FM narrava "passo a passo, [...] fato este, que contribuiu fortemente para a informação dos detalhes técnicos do evento". 28 O "excelente" 29 trabalho da emissora nas competiçóes auxiliava público e atletas a acompanharem e compreenderem o desenrolar das mesmas. De manhã cedo, convocava os surfistas e anunciava as condiçóes das ondas. Durante o dia, seus programadores criavam "um clima muito descontraído, ao som de DIRE STRAITS, PRETENDERS e THE POLICE".30 A emissora foi eleita três vezes (1989, 1991 e 1992) a "melhor rádio surfe do mundo" pela Associação dos Surfistas Profissionais (ASP). ${ }^{31}$ Da mesma forma, as coberturas da Bandeirantes FM (São Paulo) ganharam elogios de Fluir: "diretamente de Itamambuca para São Paulo, num excelente trabalho jornalístico da equipe comandada por Lizandro Antonio".32 A presença de emissoras de rádio e televisão era vista como uma contribuição para o crescimento do esporte e ao mesmo tempo um sintoma de seu sucesso.

Antes de passar ao próximo item, resta mencionar duas maneiras pelas quais o surfe esteve presente em certas emissoras, as quais auxiliaram a divulgação e crescimento da modalidade e, em contrapartida, ganharam audiência e prestígio entre os aficionados. Primeiro, as rádios que noticiavam as condições do mar através de entradas na programação conhecidas como informativo das ondas ou boletim das ondas. Este tipo de serviço atraía a audiência de surfistas, sendo às vezes patrocinado por empresas ligadas à modalidade, como ocorria com a Gazeta FM de São Paulo. ${ }^{33}$ Segundo, programas especializados como o semanal "Surf Show" (Pool FM, São Paulo capital), dirigido por "um surfista das antigas, o conceituado Julinho Mazzei" com "controle de qualidade e toda a assessoria editorial da Revista Fluir", trazendo "música, entrevistas e informaçóes de ondas, tempo, estradas". 34

\section{Surfe e audiovisual}

Há uma relação próxima e de longa data entre esporte e cinema (MELO, 2003, 173). No caso da modalidade esportiva em discussáo, "a cultura surfe californiana rapidamente se difundiu pelo anel do Pacifico, inicialmente através de um gênero hollywoodiano de filmes de praia" (BOOTH, 2001, 91). Isto não se 
deu por acaso: na Califórnia estão sediados os estúdios cinematográficos mais poderosos do mundo. Na passagem, o historiador australiano Douglas Booth associa a disseminação da cultura surfe à mídia desde o princípio. Mas quando se deu este início?

O autor estabelece um marco: "produtores de Hollywood identificaram cedo o potencial comercial da nova cultura e a Columbia Pictures lançou o gênero hollywoodiano em 1959 com Gidget" (BOOTH, 2001, 91), uma adaptação do livro homônimo de Frederick Kohner, que vendera bastante (SCOTT, 2005). O filme foi um grande sucesso de bilheteria. Duas articulaçôes se dão nesse momento: cultura do surfe e mídia; cultura do surfe e lucro/entretenimento/ exploração comercial. Ambas, embora contestadas de diversas formas e submetidas a tensões, não se quebraram desde então. Vários filmes sobre praia (beach party films) cuja trama destacava o surfe foram realizados na primeira metade da década de 1960. "As histórias de praia de Hollywood eram aventuras musicais e ajudaram a popularizar a surf music", estilo musical que tem no grupo Beach Boys o expoente máximo. Os discos de surf music obtiveram tremendo sucesso comercial. A veiculação de canções de astros da música pop durante os filmes contribuía para a vendagem dos discos com a trilha sonora (Booth, 2001, 93).

O sucesso dos filmes esteve longe de representar unanimidade: muitos praticantes reclamavam da imagem pasteurizada da modalidade produzida por Hollywood. Um contraponto ao olhar dos grandes estúdios era o das produçôes caseiras, iniciadas em 1930. Duas décadas depois, começou, de forma precária (gravação, edição, exibição etc.) a realização de filmes especializados (BOOTH, 2005, 106). Configura-se o quadro no qual Booth (2001) estabelece duas categorias: filmes hollywoodianos (foco na "vida praiana") e filmes de surfe especializados (foco em "camaradagem do surfári, ondas grandes, ondas perfeitas, locais exóticos e 'secretos', novos desenhos de prancha e manobras"). Os primeiros se dirigem a um público amplo; os últimos, a jovens surfistas (BOOTH, 2001, 94; SCOTT, 2005). O cinema, portanto, é um dos setores em que se travam disputas por representação em torno do esporte.

Para Booth (2001, 95), mais do que tipos de produção, a dicotomia representa formas distintas de encarar e construir valores:

Diferentemente do gênero hollywoodiano que retratava o surfe como um passatempo conformista, os homens e mulheres jovens nos filmes de surfe especializados, que desciam ondas e viajavam incessantemente, e que nunca trabalhavam ou se preocupavam, carregavam a mensagem potencialmente subversiva de que surfistas eram menos previsiveis, menos confiáveis e não tão prontos a se conformar.

Nesta interpretação, os filmes especializados seriam um canal para divulgação da rebeldia e inconformismo característicos da subcultura do surfe na Califórnia. Exibidas fora dos grandes circuitos, as películas eram recebidas com avidez pelos interessados em surfe: "ao fim da década [de 1950], milhares de entusiastas e fäs se reuniam em clubes privados e salóes públicos para assistir a filmes especializados" (BOOTH, 2001, 94). Porém, seu alcance não deve ser exagerado, uma vez que tais espaços recebiam audiências significativamente 
menores em relação às dos filmes hollywoodianos. Para Booth (2001, 95), a diferença tem relação direta com o conteúdo: "o público pequeno dos filmes de surfe especializados significava que o potencial subversivo de uma cultura puramente hedonista permanece altamente restrito - ao menos naquele momento".

$\mathrm{O}$ autor confere papel central aos meios de comunicação na expansão desta visão de surfe para além da Califórnia, entre fim dos anos 1950 e início da década seguinte: "a subcultura do surfe californiana se difundiu para a Austrália com surfistas visitantes, filmes especializados e revistas". Publicaçôes como Surfer, Surfing World e Tracks surgiram com o objetivo específico de divulgar filmes, tanto na Austrália quanto nos EUA. Fizeram tanto sucesso que se tornaram periódicas (BOOTH, 2001, 95-6, citação à 95; SCOTT, 2005).

Dias (2008) defende a idéia de que não se pode dissociar a disseminação do surfe e seu intenso caráter imagético da larga influência cultural que os EUA exercem sobre o Brasil e sua classe média a partir da segunda metade do século XX. Nos anos imediatamente anteriores à criação de Fluir, houve uma significativa produção cinematográfica nacional em que a modalidade ocupava papel relevante: Nas ondas do surf (1978), Nos embalos de Ipanema (1978), Menino do Rio (1981) e Garota dourada (1983), os três últimos dirigidos por Antonio Calmon. ${ }^{35}$ Todos tiveram grandes bilheterias e contribuíram para divulgar o esporte e seu estilo de vida junto ao público brasileiro. Somam-se a estes os filmes hollywoodianos exibidos no cinema e/ou na televisão.

O cinema é fundamental para a configuração da subcultura do surfe e para as disputas de valores no seu interior (STEDMAN, 1997; FISHER, 2005). Isto pode ser percebido, por exemplo, pelas referências às projeçóes nas festas e eventos noturnos durante os principais campeonatos: "No final, à noite na boite New 88 todos os surfers fizeram um encontro, onde rolavam todas e onde foi exibido o filme Bali High [...]".36 Fluir divulgava e publicava anúncios de sessôes especiais de filmes ou vídeos estrangeiros de surfe que itineravam por algumas cidades. ${ }^{37} \mathrm{O}$ anúncio de Follow The Sun, por exemplo, trazia datas e locais em São Paulo, Rio de Janeiro e Niterói e a previsão de sessôes em Santos e Porto Alegre. ${ }^{38} \mathrm{O}$ texto sobre Adventures Paradise elogiava detalhes técnicos da película e da empresa responsável por trazê-la ao país, além de descrever a atmosfera de tais sessóes:

$$
\begin{aligned}
& \text { ir ver um filme de surfé sempre um momento clássico, em que a rapaziada, num clima } \\
& \text { de muita fissura e energia, acompanha os melhores surfistas do mundo em aventuras } \\
& \text { que são a matéria-prima dos sonhos de todos nós - ondas perfeitas, lugares exóticos e } \\
& \text { maravilhosos. ("Cinema - O filme Adventures Paradise", Ivo Piva Imparato, Fluir n. } \\
& \text { 7, dez 1984, 131.) }
\end{aligned}
$$

Menos numerosos foram os anúncios de venda de vídeos oficiais de competiçôes, como os das etapas do Circuito Mundial disputadas em Florianópolis em 1986 e 1987.39

O cinema recebe menos espaço que a música, mas está igualmente presente desde o lançamento de Fluir, com um texto sobre o filme "The Wall" (por sinal intimamente ligado à música). ${ }^{40}$ Segue-se a publicação intermitente 
de artigos sobre filmes com temática ligada a esportes radicais até a criação de uma seção de vídeo em 1988, quando as locadoras de fitas VHS estavam na moda no Brasil, ao menos entre a classe média. ${ }^{41} \mathrm{O}$ mercado de vídeos de surfe inclui desde produçôes caseiras até vídeos oficiais de campeonatos e promocionais (financiados por patrocinadores). A circulação desse material varia muito, sendo mais restrita aos adeptos da cultura do surfe: em geral eram vendidos por reembolso postal e, em casos raros, encontrados em locadoras; havia exibiçôes públicas nos moldes mencionados anteriormente; cópias oficiais ou piratas circulavam entre os membros da subcultura e eram assistidas nas residências, individualmente ou em grupo. Nos últimos anos, adventos como internet, digitalização e barateamento do custo de cópias aumentaram consideravelmente o número de títulos e a circulação: são vendidos, vistos e baixados na internet e continuam circulando por meios tradicionais (ofertados como brinde na compra de revistas ou alugados em locadoras especializadas).

$\mathrm{Na}$ televisão, novelas que abordavam a cultura de praia - como Água Viva (1980) - atuaram na mesma direção. Fluir destacou a participação do ator paulista Kadu Moliterno, que "passou a acompanhar surfistas para aprender seus costumes e sua linguagem, uma vez que seu sotaque de paulista, filho de italianos, não era o que se poderia chamar de ideal para o papel" na novela $O$ Pulo do Gato (1978), da Rede Globo. Moliterno tornou-se surfista e interpretou personagens ligados ao esporte em produçóes como Partido Alto (1984), que teve seqüências filmadas no Havaí, onde foi "acolhido" pelo "mundo do surfe". Um artigo destaca a contribuição do artista por retratar o surfe "com uma imagem limpa e positiva". Como resultado, "conseguiu prender-nos todos à televisão por uns bons dois meses... E prá ver novela!"’2 $\mathrm{Na}$ edição seguinte, Carlos Lorch reiterou os elogios e estendeu-os: "Werner e Marcos, interpretados por Kadu Moliterno e André de Biase [sic], eram ali, para todos os surfistas, os embaixadores do surfpara o mundo dos 'outros'. E, como embaixadores, cumpriram bem seus papéis. ${ }^{\text {"43 }} \mathrm{Na}$ seqüência, o próprio ator explicava o trabalho com André de Biasi no Havaí foram responsáveis pela produção, contratação de equipe etc. - e ressaltava o privilégio de trabalhar nas férias surfando no arquipélago, com as despesas pagas pelo empregador. ${ }^{44}$ Nota-se o reconhecimento da televisão como mídia que fala a todos, daí a preocupação com a imagem dos surfistas: colocar dois deles no horário nobre da TV significa que aquela caracterização representará, para milhôes de pessoas, o que é o esporte. Desde entấo, o surfe apareceu em diversas novelas - Top Model (1989-90), Vira-Lata (1996), Corpo Dourado (1998), Da Cor do Pecado (2004) 45 -, duas delas de autoria de Antonio Calmon.

Na mesma TV Globo, o seriado Armação Ilimitada (1985-88) obteve grande sucesso e introduziu uma série de inovaçóes na linguagem televisiva brasileira (CANNITO E TAKEDA, 200346; MAIOR, 2006). Protagonizado pela dupla Moliterno e Biasi, que viveram Juba e Lula, surfistas e praticantes de esportes na natureza como montanhismo e mergulho, teve como coordenador artístico e um dos roteiristas Antonio Calmon, contratado pela emissora por sua capacidade de comunicação com o público juvenil (RAMOS, 1995, 101). Armação combinava linguagens e temas de interesse dos jovens, como histórias em quadrinhos, rock, esportes radicais, cinema e música, e foi decisivo 
para transformar o surfe em moda no Brasil (RAMOS, 1995, 77; MIRA, 2001; CANNITO E TAKEDA, 2003). Inspirado em Menino do Rio e Garota Dourada, eis o cerne da trama:

Sáo quatro personagens vivendo aventuras, romances e constituindo uma família alternativa. Dois surfistas (Juba e Lula) sócios de uma empresa de prestaçôes de serviço chamada "Armação Ilimitada", dublês e praticantes de esportes radicais que vivem a paquerar e a disputar mulheres, adotam um menor abandonado ("Bacana") e namoram uma jornalista (Zelda Scott) feminista e independente, mas também romântica e sonhadora (CANNITO E TAKEDA, 2003).

Para os autores, esse núcleo central representava uma contestação do "modelo tradicional de família nuclear e monogâmica" e, junto com a abordagem de problemas brasileiros como o dos povos indígenas e das crianças abandonadas e as inovaçóes estéticas, insere o programa nas tentativas de experimentação frente à censura, em meio à abertura política. Assim como Mira (2001), Cannito e Takeda (2003) destacam o impacto do seriado: "Esse tom anárquico e a irreverência do programa marcaram época influenciando os hábitos e o imaginário dos jovens [...]". O sucesso foi tão grande que os protagonistas criaram uma empresa (Kadu e André Promoçóes Artísticas) com o objetivo de licenciar produtos com a marca Juba \& Lula, lançando dezenas de itens como roupas e acessórios, história em quadrinhos e o LP "Juba e Lula - o disco". Um longametragem foi planejado, mas não chegou a ser produzido (BRYAN, 2004, 284; MIRA, 2001, 165).

Mas a presença dos esportes radicais na telinha náo se limitou à dramaturgia. Em 1983 estreava o primeiro programa especializado neles da TV brasileira: Realce. Segundo Antonio Ricardo, um dos fundadores, a idéia de criar a revista Realce, precursora do programa televisivo, surgiu quando Brasil Surf acabou. ${ }^{47}$ Realce deixou de circular como impresso e teve seu conteúdo e formato adaptados para a televisão, tornando-se fundamental para a divulgação e consolidação do surfe no Brasil. Além de reportagens sobre a modalidade, cobria skate, vôo livre, windsurf e música. Veiculado na TV Record do Rio de Janeiro, era retransmitido para outros estados (BRYAN, 2004, 281). Entre os programas de televisão que abriram espaço para o surfe é possível citar ainda Videosurf, com Ivo Piva Imparato e Tonico Mello. ${ }^{48}$

A presença na tevê ajudava a atrair curiosos, interessados e adeptos. Fluir elogiava estas apariçóes e a exibição de reportagens sobre campeonatos em telejornais locais. Neste contexto, a cobertura dos meios de comunicação sobretudo da mídia náo-especializada - era tomada pelos envolvidos com as competiçốes como prova irrefutável do crescimento dos esportes radicais e do interesse da sociedade em relação a eles.

Ainda no que diz respeito às relações entre televisão e surfe, Rico de Souza afirma ter trazido, entre 1976 e 1988 (sem especificar o ano) "os primeiros filmes de surf para a televisão brasileira, que eram exibidos no Esporte Espetacular [programa da TV Globo]. Isso ajudou a disseminar o esporte entre nós" (SOUZA, 2004, 54). 
Por fim, cabe destacar que alguns órgãos de mídia patrocinaram atletas. O mesmo Rico diz ter sido patrocinado pela TV Globo "de 1976 a 1988" (SOUZA, 2004, 54). Uma foto dos finalistas do "campeonato brasileiro, Saquarema, 1978" mostra Rico e outro surfista cujo patrocinador principal era uma empresa de comunicação: Cauli Rodrigues, com adesivo da Rádio Cidade na prancha (SOUZA, 2004, encarte entre 80-1). No final de 1983, a emissora FM A Tribuna de Santos ajudou a patrocinar a ida de Picuruta e Almir Salazar ao Havaí. ${ }^{49}$

\section{Considerações finais}

Durante a segunda metade do século XX, manifestações artísticas e midiáticas de naturezas e características diversas estiveram relacionadas com o surfe. Frequentemente veiculadas pelos meios de comunicação de massa, elas participaram ativamente da construçáo de imagens em torno da modalidade e ajudaram-na a se tornar conhecida e admirada ao redor do mundo, tendo como uma das principais consequências a expansão da moda surf para diversos países e continentes.

No Brasil, o processo sofreu notável impulso nos anos 1980 e foi crucial para a popularização do surfe naquela década. O panorama apresentado neste trabalho pretende contribuir para a compreensão de que o crescimento, profissionalização e comercialização experimentados pela modalidade no período têm como um de seus motores as representaçôes midiáticas. Ou seja, nas manifestaçôes da cultura pop e da comunicação de massa, tais como música, cinema e programas de rádio e televisão, o surfe apareceu para um público amplo. Uma parte dessas pessoas interessou-se pelo esporte e pelos valores a ele associados, passando a consumir produtos e a desejar aproximar-se do que se considerava um estilo de vida. Essa popularização, por sua vez, simultaneamente possibilitou e resultou em transformaçóes na modalidade no Brasil.

\section{Notas}

${ }^{1}$ Trabalho apresentado no XXXII Congresso Brasileiro de Ciências da Comunicação. Este artigo remonta a discussóes travadas na tese de doutorado $O$ surfe nas ondas da midia: um estudo de Fluir nos anos 1980, defendida em 2009 no PPGCOM/UFF. $\mathrm{O}$ autor agradece à Fundação de Amparo à Pesquisa do Estado do Rio de Janeiro (FAPERJ) a bolsa concedida durante parte do doutorado.

${ }^{2}$ Para uma discussão do conceito de subcultura, ver Fortes (2009, especialmente 151-63).

3 "Esse tal de rock'n'roll", Chacal, Fluir n. 1, set-out 1983, 10.

${ }^{4}$ Fluir n. 2, nov-dez 1983, 65.

5 "Devo - o som dos anos 80", Paulo de Oliveira Brito (Anshowinhas), Fluir n. 3, mar 1984, 59.

6 "Stones, explosão subterrânea com cheiro de sexo e suicídio ou isso deve ser o inferno", por Pepe Escobar, Fluir n. 3, mar 1984, 58.

7 “Som”, Fluir n. 4, mai 1984, 79

${ }^{8}$ De acordo com Caiafa $(1985,74-7)$, entre os punks do Rio de Janeiro circulavam 
revistas importadas de skate como Skateboarder, Thrasher e TWS. Os exemplares passavam de mão em mão e traziam mais do que conhecimento sobre o esporte: através das informaçóes e indicaçôes sobre música, os skatistas conheceram bandas estrangeiras e gradualmente aderiram ao punk e ao hardcore. O punk carioca foi aos poucos se transformando num "movimento" independente do skate. Na primeira metade da década, muitos punks compareciam aos campeonatos de skate: uns para competir, outros para participar (da platéia das provas, durante o dia; e das festas e atraçóes musicais, à noite).

${ }^{9}$ Agradeço a Edmundo de Drummond Alves Júnior por chamar minha atenção para este ponto.

10 "Craig Paterson", Alexandre Andreatta, Fluir n. 12, out-nov 1985, 118-9.

11 "Quem é Tchap-Tchura”, Reinaldo Negreiros Ribeiro, Fluir n. 4, mai 1984, 66.

${ }^{12}$ Fluirn. 4, mai 1984,70. O skatista em questão integrava uma das bandas acompanhadas na pesquisa sobre os punks do Rio de Janeiro realizada por Caiafa (1985).

13 "Rock in Rio Festival", Fluir n. 6, set 1984, 108.

${ }^{14}$ Ver as declaraçôes de vários deles no filme Paralamas em Close-Up. Sobre a Fluminense FM, ver Mello (1992) e Silva (2008).

${ }^{15}$ Fluir n. 6, set 1984, 26-7.

${ }^{16}$ Fluir n. 7, dez 1984, 123.

${ }^{17}$ Fluir n. 20, mai 1987, 4-5.

18 Fluir n. 12, out-nov 1985, 130.

${ }^{19}$ Fluir n. 26, dez 1987, 127.

${ }^{20}$ Fluir n. 20, mai 1987, 127.

${ }^{21}$ Fluir n. 2, nov-dez 1983, 67.

22 "Rádio Fluir", Fluir n. 23, set 1987, 98.

23 "Ultraje a Rigor", entrevista a Alceu Toledo Junior, Célia Almudena e Alexandre Andreatta, Fluir n. 11, ago-set 1985, 112-6.

24 “Entrevista Replicantes”, Fluir n. 15, mai 1986, 120.

25 "Som", Paulo de Oliveira Brito, Fluir n. 6, set 1984, 108.

26 "Dr. Anshowinhas Responde", Fluir n. 6, set 1984, 99.

27 "A verdadeira história de surf de Saquarema”, Otávio Pacheco, Fluir n. 27, jan $1988,77$.

28 "Itacoatiara", Elvio Pereira, Fluir n. 6, set 1984, 37-40.

29 "O campeonato de Itacoatiara”, Fred D’Orey, Fluir n. 6, set 1984, 27.

30 "Itacoatiara", Elvio Pereira, Fluir n. 6, set 1984, 37-40.

31 Entidade máxima do surfe, a ASP organiza os circuitos mundiais profissionais. "ASP Awards", sítio da ASP. Disponível em <http://www.aspworldtour.com/2008/ pdf/aspawards.pdf>. Consulta em 22/4/2008.

32 "Campeonatos universitários", Bruno C. Alves, Fluir n. 3, mar 1984, 38-9.

33 “Toques", Fluir n. 7, dez 1984, 124. 
${ }^{34}$ Fluir n. 8, fev 1985, 102.

35 Para uma análise dos quatro filmes e de suas relaçóes com o contexto brasileiro da época, ver Melo e Fortes (2009). Para uma análise da articulação entre os filmes de Calmon e merchandising, moda, música e cultura jovem, ver Bueno (2005), especialmente 165-80.

36 Bruno C. Alves, "3‥ Festival Olympikus de Surf”, Fluir n. 3, mar 1984, 18-23.

37 "Coluna Social", Fluir n. 5, jul 1984, 12.

38 Fluir n. 10, jun-jul 1985, 61.

39 Fluir n. 26, nov 1987, 102.

40 Fluir n. 1, set-out 1983, 46. O filme inspira-se no disco homônimo do grupo Pink Floyd.

41 "Drop-Out Vídeo", Davilson Ribeiro, Fluir n. 28, fev 1988, 104.

42 "Gente que surfa - Kadu Moliterno", Carlos Lorch, Fluir n. 6, set 1984, 24.

43 "Tubos na TV", Carlos Lorch (t), Gordinho (f), Fluir n. 7, dez 1984, 32-3.

44 "Um papel para poucos", Kadu Moliterno, Fluir n. 7, dez 1984, 34-5.

${ }^{45}$ Para informaçôes sobre as novelas, ver Memória Globo. Disponível em <http:// memoriaglobo.globo.com/Memoriaglobo/upload/0,27723,5265,00.html>. Acesso em 06/06/2010.

${ }^{46}$ Agradeço aos autores o gentil envio do artigo.

${ }^{47}$ Cláudia Cecília, "Realce: feliz aniversário", Zine, Jornal do Brasil, 18/4/1993, 12-3.

48 Ivo Piva Imparato, Fluir n. 10, jun-jul 1985, 24-5.Em 1988, ia ao ar em São Paulo o programa Grito da Rua, que focava o skate (HONORATO, 2004). No Rio, Vibração fazia uma dobradinha com Realce e abordava a mesma modalidade (MIRA, 2001; HONORATO, 2004).

49 "Picuruta", entrevista, Fluir n. 2, nov-dez 1983, 32. 


\section{Referências bibliográficas}

BEATTIE, Keith (2003). Radical Delirium: Surf Film, Video and the Documentary Mode. In: Some Like It Hot: The Beach as a Cultural Dimension. SKINNER, James; GILBERT, Keith; EDWARDS, Allan (eds.). Oxford: Meyer \& Meyer Sport, 129-53. (Sport, Culture \& Society, v. 3)

BOOTH, Douglas (2001). Australian Beach Cultures: The History of Sun, Sand and Surf. London: Frank Cass.

BOOTH, Douglas (2005). Paradoxes of Material Culture: The Political Economy of Surfing. In: NAURIGHT, John; SCHIMMEL, Kimberly S. (ed.) The Political Economy of Sport. Basingstoke and New York, Palgrave Macmillan, 104-25.

BORGES, Luís Fernando Rabello (2003). O processo inicial de formulação de produtos de midia impressa brasileira voltados ao público jovem - Um estudo de caso da revista Pop. Dissertação de mestrado, Programa de Pós-Graduação em Ciências da Comunicação, Universidade do Vale do Rio dos Sinos (Unisinos).

BOURDIEU, Pierre (1990). Programa para uma sociologia do esporte. In: Coisas ditas. São Paulo: Brasiliense, 207-220.

BRYAN, Guilherme (2004). Quem tem um sonho não dança: cultura jovem brasileira nos anos 80 . Rio de Janeiro: Record.

BUENO, Zuleika de Paula (2005). Leia o livro, veja o filme, compre o disco: a produção cinematográfica juvenil brasileira na década de 1980. Tese de doutorado em multimeios, Universidade Estadual de Campinas. Disponível em $<$ http://libdigi.unicamp.br/document/?code $=v t l s 000382800>$. Acesso em $9 / 8 / 2008$.

CAIAFA, Janice (1985). Movimento punk na cidade: a invasão dos bandos sub. Rio de Janeiro: Jorge Zahar.

CANNITO, Newton; TAKEDA, Marcos (2003). Armação Ilimitada e os potenciais da fiç̧ão televisiva. Mimeo.

CASTRO, Ana Lúcia de (2003). Culto ao corpo e sociedade: mídia, estilos de vida e cultura de consumo. São Paulo: Annablume/Fapesp.

DIAS, Cleber Augusto Gonçalves (2008). Urbanidades da natureza: o montanhismo, o surfe e as novas configuraçôes do esporte no Rio de Janeiro. Rio de Janeiro: Apicuri. (Sport: História)

FISHER, Kevin (2005). Economies of Loss and Questions of Style in Contemporary Surf Subcultures. Junctures: The Journal for Thematic Dialogue, Dunedin, n. 4 jun, 13-20. Disponível em <http://www.junctures.org $/$ issues.php?issue $=04 \&$ title $=$ Movement $\&$ colour $=\operatorname{rgb}(243,174$, 0)>. Acesso em 07/11/2008.

FORTES, Rafael (2009). O surfe nas ondas da mídia: um estudo de Fluir nos anos 1980. Tese de doutorado, Programa de Pós-Graduação em Comunicação, Universidade Federal Fluminense. 
FORTES, Rafael; MELO, Victor Andrade de (2009). O surfe no cinema brasileiro. In: DIAS, Cleber Augusto Gonçalves; ALVES Junior, Edmundo de Drummond (org.). In busca da aventura: repensando o esporte, o lazer e a natureza. Niterói: EdUFF (no prelo).

GOLDENSTEIN, Gisela Taschner (1991). Lazer operário e consumo cultural na São Paulo dos anos oitenta. Revista de Administraçáo de Empresas, São Paulo, v. 31, n. 3, 13-35, jul-set . Disponível em <http://www.rae. com.br/rae/index.cfm?FuseAction $=$ Artigo $\& I D=792 \&$ Secao $=$ ARTIGO S\&Volume=31\&numero=3\&Ano=1991 $>$. Acesso em 18/8/2008.

GUTENBERG, Alex (1989). A história do surf no Brasil: 50 anos de aventura. São Paulo: Grupo Fluir/Ed. Azul.

HONORATO, Tony (2004). Uma história do skate no Brasil: do lazer à esportivização. In: XVII Encontro Regional de História, Anpuh-SP, Unicamp, Campinas, 6-10/9.

MAIOR, Marcel Souto (2006). Almanaque da TV Globo. Rio de Janeiro: Globo.

MELLO, Luiz Antonio (1992). A onda maldita: como nasceu a Fluminense FM. Niterói: Arte \& Cultura.

MELO, Victor Andrade de (2003). Memórias do esporte no cinema: sua presença em longa-metragens brasileiros. Revista Brasileira de Ciências do Esporte, Campinas, v. 25, n. 1, 173-188. Disponível em <http://www.rbceonline.org. br/revista/index.php/RBCE/article/view/183/190>. Acesso em 19/11/2008.

MELO, Victor Andrade de; FORTES, Rafael (2009). O surfe no cinema e a sociedade brasileira na transição dos anos 1970/1980. In: MELO, Victor A.; DRUMOND, Mauricio (org.). Cinema e esporte: novos olhares. Rio de Janeiro: Apicuri, 185-220.

MIRA, Maria Celeste (2001). O leitor e a banca de revistas: a segmentação da cultura no século XX. São Paulo: Olho d'Água/Fapesp.

PILATTI, Luiz Alberto (2006). A lógica da produção do espetáculo: o esporte inserido na indústria do entretenimento. Revista de Economia Política de las Tecnologias de la Información y Comunicación, vol. VIII, n. 2, mayo-ago. Disponível em <http://www2.eptic.com.br/arquivos/ Revistas/VIII,n.2,2006/LuizPilatti.pdf>. Acesso em 6/3/2008.

RAMOS, José Mario Ortiz (1995). Televisão, publicidade e cultura de massa. Petrópolis: Vozes.

SCOTT, Paul (2005). Australian Surfing Magazines: The First Wave (1961-1962). In: Journalism Education Conference, Griffith University, Surfers Paradise (Austrália), 29 nov - 2 dez.

SILVA, Heitor Luz da (2008). Rádio FM, Rock e Rio de Janeiro: uma análise das estratégias de incursão da "Fluminense Maldita" e da "Cidade do Rock" no dominio das guitarras. Dissertação de mestrado, Programa de Pós-Graduação em Comunicação, Universidade Federal Fluminense. 
SOUZA, Rico de (2004). Boas ondas: surfando com Rico de Souza. Rio de Janeiro: Ediouro.

STEDMAN, Leanne (1997). From Gidget to Gonad Man: surfers, feminists and postmodernisation. Australian and New Zealand Journal of Sociology, v. 33, n. 1, março, 75-90.

VILLAÇA, Renato Costa (2002). O Rock e as bases de uma cultura musical pop. In: XI Encontro Anual da Compós, UFRJ, Rio de Janeiro, 04-7/6. Disponível em <http://www.compos.org.br/data/biblioteca_119. PDF $>$. Acesso em 21/1/2008.

WHEATON, Belinda; BEAL, Becky (2003). Keeping It Real: Subcultural Media and the Discourses of Authenticity in Alternative Sport. International Review for the Sociology of Sport, 38:2, 155-76. 